In order to check the hypothesis of the similarity of isoline systems for accumulation and ablation, all the final values for each year and measured at different points have been normalized according to their mean value for each year.

The normalized maps turned out to be similar to each other. Using the regular net of points, we calculated the variation coefficient of normalized values. They were smaller by 0.20 for the whole area of the maps of normalized ablation and for the greater part of the map area of normalized accumulation. A map of mean normalized values was compiled for 11 years. The isoline "unit" on it coincided with the many-year firn line. With the help of this topological map, one can compile maps for distribution of ablation and accumulation on a glacier for any year or moment, for which there are data on the location of the nourishment line or snow line according to a remote-sensing image and for which air temperature at the altitude of these lines may be estimated.

In conclusion, the degree of similarity of the maps of component isolines for the glacier mass balance between different glaciers of the same morphological type was analyzed. For this, we used normalization of not only the characteristics of the glaciers' mass balances but also of morphological characteristics (altitudinal change, width, etc.). The results point to similarity of distribution of accumulation and ablation among glaciers. This will allow us to extrapolate the principal features of the isoline maps and the described methods of calculation from the studied glaciers to unexplored ones.

\title{
SATELLITE-ALTIMETER MEASUREMENTS OF SURFACE HEIGHT IN SEA-ICE AREAS
}

\section{(Abstract)}

\author{
by
}

S.W. Laxon and C.G. Rapley

(Mullard Space Science Laboratory, University College London, Dorking, Surrey RH5 6NT, U.K.)

\section{ABSTRACT}

The Seasat radar altimeter was designed to operate over the open ocean and encountered problems over sea ice. In particular, the on-board measurements of surface height were noisy and unreliable. As a consequence, published mean sea-surface and geoid maps based on the Seasat on-board height estimates either omit sea-ice-covered areas or include suspect data. We have identified and investigated the problems encountered by the Seasat altimeter over sea ice and have developed a technique for extracting accurate surface-height values from the sea-ice echo wave-form data. The retracking method is based upon fitting real wave forms to a library of model returns.

\section{CHARACTERISTICS OF ALTIMETRY SIGNATURES OVER SEA ICE}

\section{(Abstract)}

\author{
by
}

N.F. McIntyre and S.W. Laxon

(Mullard Space Science Laboratory, University College London, Dorking, Surrey RH5 6NT, U.K.)

\begin{abstract}
We report characteristics of Seasat altimetry signatures recorded over Antarctic sea ice. Up to four discrete zones can at times be seen in characteristic sequences in the Weddell and Ross Seas, and elsewhere. They are substantially larger than those reported in the Arctic, covering up to $2500 \mathrm{~km}$ at the time of maximum ice extent in 1978 . Transitions between them can be abrupt, with marked changes occurring in less than a few kilometres. Some zones were found to persist through the 3 month satellite lifetime; others exhibited intermittent variations. Repeat data coverage has enabled temporal as well as spatial patterns to be investigated.
\end{abstract}

Interpretation of the geophysical cause of the patterns observed has been limited by available data. Some comparisons may be made with surface measurements of nadir back-scatter on first- and multi-year floes but these account for only a small proportion of the altimetry returns studied. Correlations with the NOAA Navy Ice Charts show significant disparities in the determination of the ice edge which may relate to the sensitivity of the altimeter to the presence of fresh ice or ice in very small quantities. Similar signatures can be found next to small coastal leads at the continental margin, an area known to be important for the growth of new ice. 